\title{
JUSTIÇA, CORRUPÇÃO E PODER: A EDUCAÇÃO COMO INSTRUMENTO DE COMBATE A POBREZA
}

\author{
Regina Célia Martinez ${ }^{1}$ \\ Pablo Jiménez Serrano ${ }^{2}$
}

\begin{abstract}
Resumo
A proposta central do presente estudo é discutir a correlação possível entre Poder Público, Corrupção e Justiça social. É objeto de preocupação com a concepção histórica e contemporânea dos construtos Ética Pública, Corrupção, Justiça e Justiça social. Com base numa abordagem conceitual e axiológica, discute-se a Justiça como um conceito abstrato, vago e relativo, mas que pode ser definido de acordo com a finalidade da Filosofia moral e o Direito em face da convivência humana. Conclui-se que a Justiça social é a premissa fundamental para a concretização dos direitos e da Cidadania.
\end{abstract}

Palavras-chave: Justiça. Educação. Corrupção. Pobreza.

\section{INTRODUÇÃO}

A relação possível entre Poder, Justiça social e Cidadania é um dos temas mais relevantes para qualquer ciência que se proponha a estudar as relações políticas, econômicas e sociais dentro de um arcabouço jurídico. Em diversos trabalhos anteriores, discutimos os efeitos negativos que deriva do "Abuso do poder" e da falta de "Justiça social", problemas que colocam em crise a concretização dos Direitos Sociais, Humanos e Fundamentais, sendo,

\footnotetext{
${ }^{1}$ Doutora em Direito pela Pontifícia Universidade Católica de São Paulo (1998). Professora Titular Doutora do Centro Universitário das Faculdades Metropolitanas Unidas. Professora pesquisadora do Centro Universitário das Faculdades Metropolitanas Unidas. Professora titular Doutora dos cursos de Graduação da Faculdade de Direito, Professora titular Doutora Pós-Graduação Lato Sensu de Direito Ambiental Empresarial, Professora titular Doutora do Curso de Mestrado em Direito da Sociedade da Informação da UNIFMU. Professora da Escola Paulista da Magistratura de São Paulo (EPM). Membro efetivo das seguintes Comissões da OAB/SP: Comissão Permanente de Meio Ambiente da OABSP, Coordenadora e Secretária Adjunta da referida Comissão; membro da Comissão de Direitos da Pessoa com Deficiência; membro da Comissão de Ensino Jurídico, membro da Comissão de Infraestrutura, logística e desenvolvimento sustentável, membro da Comissão OAB vai à Faculdade. Assessora do Comitê de Análise da Sociedade Brasileira para o Progresso da Ciência - São Paulo. Membro de Comissão Julgadora da Fundação de Amparo à Pesquisa do Estado de Minas Gerais. Consultora da Associação Paulista dos Conservadores e Restauradores de Bens Culturais. Consultora Especialista do Conselho Estadual de Educação - São Paulo. Editora da Revista Brasileira de Meio Ambiente Digital e Sociedade da Informação. Representante da OAB/SP como Membro Suplente, no Comitê da Bacia Hidrográfica do Alto Tietê - CBH - AT, no biênio 2015-2017. E-mail: reginamarar@uol.com.br

${ }^{2}$ Doutor em Direito pela Faculdade de Direito da Universidade do Oriente, Cuba. Professor e pesquisador do Programa de Mestrado em Direito do Centro Universitário Salesiano de São Paulo- UNISAL. Professor e pesquisador do Centro Universitário de Volta Redonda - UniFOA. Professor e pesquisador do Centro Universitário de Barra Mansa - UBM. E-mail: metodologo2001@yahoo.com.br
} 
também, um indicador determinante da negação da Cidadania.

Assim, a preocupação por significar a Justiça social tornou-se cada vez mais intensa ao vivenciar a manipulação política e o tratamento irônico dos emblemas "ordem" e "progresso". Mas, hodiernamente, significar e unificar critérios acerca da Justiça social não é tarefa fácil, pois a justiça tem-se apresentado como um construto abstrato e irrealizável ao não ter certeza do ideal social que preside a convivência e que constitui a essência do conceito.

Para onde vamos? (sentido) e o que queremos? (problema). Eis o que nos estimula a procurar por uma compreensão da Justiça social, dentre as inúmeras concepções de justiça propostas pela jusfilosofia moderna.

Nesse empenho, no presente trabalho, com base numa abordagem (investigação) conceitual e axiológica e por meio dos métodos histórico e doutrinário, discute-se o sentido da Justiça social e o abuso do poder (a corrupção) como um dos fatores que impossibilita a sua não concretização. Vê-se, por exemplo, a justiça ser vinculada a um dado ideal de "igualdade" ou de "liberdade", situando-se tais conceitos no mesmo plano ou dimensão nos mais variados discursos que têm como cerne os Direitos Humanos e Fundamentais, e mais especificamente, os Direitos Sociais.

As diversas doutrinas parecem sugerir uma noção particular de justiça. Assim, "desde Platão e Aristóteles, passando por Santo Tomás, até os juristas, moralistas e filósofos contemporâneos, todos estão de acordo sobre esse ponto. A ideia de justiça consiste numa certa aplicação de conceito de igualdade. O essencial é definir essa aplicação de tal forma que, mesmo constituindo o elemento comum das diversas concepções de justiça, ela possibilite as suas divergências. Isso só é possível se a definição da noção de justiça contenha um elemento indeterminado, uma variável, cujas diversas determinações ensejarão nas mais opostas fórmulas de justiça”. ${ }^{3}$

Entende-se que a noção moderna de justiça (justiça como liberdade) pode ser revista e adaptada á atual realidade, onde se prima a necessidade da concretização dos direitos: sociais, humanos e fundamentais, mesmo acima da liberdade. É o que, nas próximas linhas, iremos sustentar: é o tratamento proporcional do ser humano o que define o ideário de Justiça social a ser observado pelas sociedades modernas. Assim, será explicado, ao se falar em Justiça social deve-se deixar de lado o ideal de liberdade para privilegiar a "proporcionalidade" que é, em essência, a concepção que permitirá a edificação das condições propícias para a inclusão social e a cidadania, isto é, a inserção do ser humano no contexto em que vive. É a proporcionalidade, o "conceito-essência" mais apropriado a fim de possibilitar a Convivência Social. Nessa senda colocamos a Justiça social que ora se projeta em função do bem-estar e da felicidade, sendo a proporcionalidade uma condição necessária da Justiça social: os alicerces da ordem, da paz, do desenvolvimento ou do progresso. 


\section{JUSTIÇA SOCIAL}

Antes de se apresentar o conceito de justiça social faz-se mister uma breve síntese sobre o conceito de Justiça. De acordo com Perelman, justiça "é o que há de mais primitivo na alma humana, de mais fundamental na sociedade, de mais sagrado entre as nações e o que as massas reclamam hoje com mais ardor"4. Justiça é o mais universal dos conceitos invocados pelos Jusnaturalistas.

Na filosofia do direito natural, de acordo com Alf Ross ${ }^{5}$, a justiça se nos apresenta como o princípio mais elevado do direito, a ideia específica do direito que está refletida em maior ou menor grau de clareza ou distorção em todas as leis positivas e é a medida de sua correção. Paralelamente a essa concepção, o autor afirma que na filosofia mais antiga encontramos outro uso, de acordo com o qual a justiça significa a virtude suprema, que tudo abrange, sem distinção entre o direito e a moral. Desse modo, a justiça pode ser entendida simplesmente como a expressão do amor ao bem e a Deus.

Invocar a justiça, diz $\operatorname{Ross}^{6}$, é como dar uma pancada numa mesa. Isso porque a ideologia da justiça conduz à intolerância e ao conflito, visto que, a ideologia da justiça é uma atitude militante de tipo biológicoemocional, para a qual alguém incita a si mesmo à defesa cega e implacável de certos interesses. Eis que a visão formal de igualdade ou justiça como estrela para a orientação político-social carece de todo significado, é possível advogar a favor de qualquer postulado em nome da justiça. Isso explica porque todas as guerras e conflitos sociais foram travados em nome do exaltado conceito de justiça. Eé demasiado esperar que isso mude no futuro.

Como princípio jurídico, a justiça delimita e harmoniza os desejos, pretensões e interesses conflitantes na vida social da comunidade. Uma vez adotada a ideia de que todos os problemas jurídicos são problemas de distribuição, o postulado de justiça equivale a uma exigência de igualdade na distribuição ou partilha de vantagens ou cargas.

A justificação da justiça pela igualdade foi formulada no século IV a.C. pelos pitagóricos, que simbolizaram a justiça como o número quadrado, no qual o igual está unido ao igual. A imagem de justiça como a de igualdade, desde então, tem se apresentado sob inumeráveis variantes. Ora, a exigência de igualdade deve ser compreendida, portanto, num sentido relativo, isto é, como uma exigência de que os iguais sejam tratados da mesma maneira. Isso significa que, como um pré-requisito para a aplicação de norma de igualdade com autonomia, é preciso que haja algum critério para determinar o que será considerado igual; em outras palavras, a

\footnotetext{
${ }^{3}$ PERELMAN, Chaïm, Ética e direito. Trad. Maria Ermantina de Almeida Prado Galvão. 2. ed. São Paulo: Martins Fontes, 2005, p. $8-14$.

${ }^{4}$ PERELMAN, Chaïm, Ética e direito. Trad. Maria Ermantina de Almeida Prado Galvão. 2. ed. São Paulo: Martins Fontes, 2005, p. 6.

${ }^{5}$ ROSS, Alf. Direito e Justiça. Trad. Edson Bini. Revisão técnica Alysson Leandro Mascaro. Bauru, São Paulo: EDIPRO, 2000, p. 313.

${ }^{6}$ Ibidem., p. 320 - 321.
} 
exigência de igualdade contida no conceito de justiça não é dirigida de forma absoluta a todos e a cada um, mas a todos os membros de uma classe, determinada por certos critérios relevantes. Em conformidade com esse fator, as diversas formulações de justiça para grupos ou contextos diversos incluem, além da ideia de igualdade, um padrão de avaliação, que deve ser aplicado como um pré-requisito à definição. ${ }^{7}$

Contudo, o conceito "Justiça" e a sua denominação "Justiça social" que, a seguir, discutiremos, a primeira vista não tem sido definidos, necessariamente, da mesma forma. Vê-se que, num primeiro momento, o ideal de justiça aparece mais estritamente ligado às "virtudes" (concepção antiga), noutro à "liberdade" (concepção moderna). E, assim, lemos na obra de Michael J. Sandel ${ }^{8}$ :

Pode-se então dizer que as teorias de justiça antigas parte da virtude, enquanto as modernas começam pela liberdade. (...). Entretanto, vale notar desde o início que essa contraposição pode levar a conclusões equivocadas.

Se voltarmos nosso olhar para os argumentos sobre a justiça que animam as diretrizes contemporâneas - não entre filósofos, mas entre homens e mulheres comuns encontraremos um quadro mais complicado. É verdade que a maior parte das nossas discussões é sobre como promover a prosperidade e respeitar a liberdade individual, pelo menos superficialmente. Entretanto, na base mesma desses argumentos, e por vezes se opondo a eles, podemos muitas vezes vislumbrar outro grupo de convicções - sobre quais virtudes são merecedoras de honras e recompensadas e que modo de viver deve ser promovido por uma boa sociedade. Apesar de sermos devotados à prosperidade e à liberdade, não podemos absolutamente desconsiderar a natureza judiciosa da justiça. É profunda a convicção de que justiça envolve virtude e escolha: meditar sobre a justiça parece levar-nos inevitavelmente a meditar sobre a melhor maneira de viver. (Grifo nosso)

Neste trabalho, o conceito de justiça social é definido como "uma dimensão da Justiça aplicada à convivência”. Diz-se de uma condição (situação) social necessária, da qual depende a inclusão social e a cidadania, por meio da qual, a partir da concepção da "proporcionalidade", há de se possibilitar a participação do cidadão no processo de desenvolvimento (produção, distribuição, intercâmbio e consumo) nacional. Assim, a "justiça social" depende da real concretização dos direitos sociais consagrados no art. $6^{\circ} \mathrm{da} C \mathrm{CF}$, em face da dignidade da pessoa humana, da redução das desigualdades sociais, da erradicação da pobreza etc.

Talvez objetivando uma consideração imparcial de Justiça social, evitando os benefícios e vantagens de algumas pessoas em detrimento a outras, alguns autores idealizaram teorias e princípios que orientassem a compreensão dos problemas políticos, sociais e econômicos e com base no lugar que ocupa cada ser humano:

\footnotetext{
${ }^{7}$ ROSS, Alf. Direito e Justiça. Trad. Edson Bini. Revisão técnica Alysson Leandro Mascaro. Bauru, São Paulo: EDIPRO, 2000, p. 315.

${ }^{8}$ SANDEL, Michael J. Justiça - O que é fazer a coisa certa. Trad. de Heloisa Matias e Maria Alice Máximo. 10. ed. Rio de Janeiro: Civilização Brasileira, 2013, p. 17-18. [Em contrapartida, filósofos políticos modernos - de Immanuel Kant, no século XVIII, a John Rawls, no século XX - afirmam que os princípios de justiça que definem nossos direitos não devem basear-se em nenhuma concepção particular de virtude ou da melhor forma de vida. Ao contrário, uma sociedade justa respeita a liberdade de cada indivíduo para escolher a própria concepção do que seja uma vida boa].
} 
suas potencialidades, dons e habilidades, concepção do bem etc. Assim, por exemplo, Rawls ${ }^{7}$, consideraria os seguintes princípios:

1. Reconhecimento de que toda pessoa tem o mesmo direito à liberdade básica mais ampla possível e compatível com a liberdade dos outros.

2. Os bens somente são distribuídos de forma desigual quando: a) essa distribuição desigual redunde em maior benefício dos demais desfavorecidos e; b) está ligada a cargos e posições abertos a todos com plena transparência e oportunidades.

Essa visão implicaria que cada pessoa deverá estar no mesmo plano de igualdade e liberdade. Assim, para poder atingir suas concepções do "bem" necessita dos mesmos bens primários, isto é, os mesmos direitos, liberdades e oportunidades básicas, assim como os mesmos meios para todos os fins, tais como ingressos, riquezas e bases sociais de autorrespeito. Daí os bens sociais primários devem distribuir-se por igual, a não ser que a distribuição desigual de tais bens redunde em benefício dos menos favorecidos. Logo, somente pode-se limitar uma liberdade (vontade) em função de outra liberdade, as liberdades básicas são prioritárias em face ao desenvolvimento socioeconômico e o princípio de igualdade de oportunidade é prioritário diante do princípio de diferencias. ${ }^{9}$

É o que se coloca atualmente na maioria das discussões sobre justiça a respeito de como distribuir os frutos da prosperidade ou os fardos dos tempos difíceis e como definir os direitos básicos dos cidadãos. ${ }^{10}$ Também, seguindo essa orientação, doutrinadores e estudiosos modernos correlacionam o conceito a vários princípios, assim, por exemplo: "a cada um segundo seus méritos"; "a cada um segundo sua contribuição"; "a cada um segundo suas necessidades"; "a cada um segundo sua posição e condição" etc. ${ }^{11}$

Assim, para se saber se uma sociedade é justa, basta perguntar como ela distribui as coisas que valoriza (renda e riqueza), deveres e direitos, poderes e oportunidades, cargos e honrarias. Uma sociedade justa distribui esses bens da maneira correta; ela dá a cada indivíduo o que lhe é devido. As perguntas difíceis começam quando indagamos o que é devido às pessoas e por quê. ${ }^{12}$

Atualmente, a ingerência da economia atinge também a moral e o direito. A noção do lucro das camadas privilegiadas economicamente, por exemplo, encontra respaldo na previsão da legalidade, através do ideal de autonomia do ser humano, da liberdade contratual e da livre concorrência. Significa dizer que toda a estrutura

\footnotetext{
${ }^{7}$ RAWLS, J. A Theory of Justice. Harvard University Press, Cambridge, Mas., 1971, p. 126-137, apud, VILLORIA Mendieta, Manuel. Ética pública y corrupción: Curso de ética administrativa. Madrid: Tecnos, 2000, p. 43.

${ }^{9}$ VILLORIA Mendieta, Manuel. Ética pública y corrupción: Curso de ética administrativa. Madrid: Tecnos, 2000, p. 43.

${ }^{10}$ SANDEL, Michael J. Justiça - O que é fazer a coisa certa. Trad. de Heloisa Matias e Maria Alice Máximo. 10. ed. Rio de Janeiro: Civilização Brasileira, 2013, p. 20.

${ }^{11}$ PERELMAN. De la justice (1945) apud ROSS, Alf. Direito e Justiça. Trad. Edson Bini. Revisão técnica Alysson Leandro Mascaro. Bauru, São Paulo: EDIPRO, 2000, p. 314.
} 
jurídica que dá respaldo legal às transações econômicas é pensada e criada por uma classe dominante que através de uma imposição ideológica mantém a sociedade sob sua tutela de forma coesa.

Contudo, no Estado moderno existe uma tendência a defende uma noção de justiça subordinada ao poder econômico das camadas sociais mais favorecidas, engendrando e legitimando, consequentemente a desigualdade social. Por esse caminho, os próprios valores, a saber, igualdade, fraternidade, solidariedade, passariam a serem considerados contrários ao ideário de Justiça social que predomina nas sociedades consumistas e regradas de forma a atender unicamente as necessidades mercadológicas.

\section{Poder e Justiça social}

Define-se "poder" como sendo a utilização normal, pelos agentes públicos, das prerrogativas que a lei lhes confere. Já, o abuso de poder fere tal prerrogativa por meio de conduta quer ilícita quer imoral do administrador. Diz-se que a conduta abusiva dos administradores é assim caracterizada quando: a) o agente atua fora dos limites de sua competência; e b) o agente, embora dentro de sua competência, se afasta do interesse público que deve nortear todo o desempenho administrativo.

Conforme Meirelles ${ }^{13}$, o "poder" (poderes administrativos) é verdadeiro instrumento de trabalho, adequado à realização das tarefas administrativas. $O$ poder administrativo é um poder instrumental, diversamente dos poderes políticos, que são estruturais e orgânicos, porque compõem a estrutura do Estado e integram a organização constitucional. Assim, os poderes administrativos nascem com a Administração e se apresentam diversificados, segundo as exigências do serviço público, o interesse da coletividade e os objetivos a que se dirigem. Dentro dessa diversidade, são classificados, consoante a liberdade da Administração para prática de seus atos, em poder vinculado e poder discricionário; segundo visem ao ordenamento da Administração ou à punição dos que a ela se vinculam, em poder hierárquico e poder disciplinar; diante de sua finalidade normativa, em poder regulamentar, e, tendo em vista os objetivos de contenção dos direitos individuais, em poder de polícia.

Esses poderes são inerentes à Administração de todas as entidades estatais - União, Estados-membros, Distrito Federal e Municípios - na proporção e limites de suas competências institucionais, e podem ser usados isolada ou cumulativamente para a consecução do mesmo ato. Tal o que ocorre, p. ex., com o ato de polícia administrativa, que é normalmente precedido de uma regulamentação do Executivo (poder regulamentar), em que a autoridade escalona e distribui as funções dos agentes fiscalizadores (poder hierárquico), concedendo-lhes atribuições vinculadas (poder vinculado) ou discricionárias (poder discricionário), para a imposição de sanções

\footnotetext{
${ }^{12}$ SANDEL, Michael J. Justiça - O que é fazer a coisa certa. Trad. de Heloisa Matias e Maria Alice Máximo. 10. ed. Rio de Janeiro: Civilização Brasileira, 2013, p. 28.

${ }^{13}$ MEIRELLES, Hely Lopes. Direito Administrativo Brasileiro. 30. ed. Atualizada por Eurico de Andrade Azevedo, Délcio Balestero Aleixo e José Emmanuel Burle Filho. São Paulo: Malheiros, 2005, p. 116 - 117.
} 
aos infratores (poder de polícia).

A Justiça social é construto que justifica os poderes. Em verdade, os poderes administrativos, como vimos, são instrumentos que objetivam a satisfação dos interesses coletivos. Eis que toda política administrativa tem como objetivo coibir toda atividade individual que possa afetar a coletividade ou pôr em risco a segurança nacional, exigindo, por isso mesmo, regulamentação, controle e contenção pelo Poder Público. ${ }^{14}$

Vejam-se as limitações e sanções ${ }^{15}$ legais impostas às liberdades pessoais (art. $5^{\circ}$, VI e VIII); ao direito de

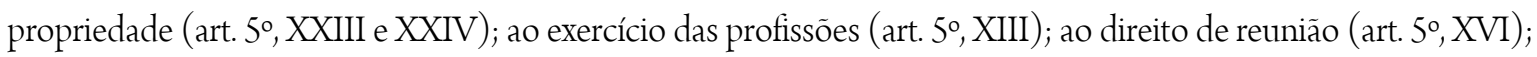
aos direitos políticos (art. 15); à liberdade de comércio (art. 170 e 173) e os condicionamentos ao exercício dos direitos individuais prescritos no Código Civil (art. 188 sobre o exercício regular de um direito reconhecido, proibindo-se o abuso) e o respeito à normas administrativas e ao direito dos vizinhos (arts. 1.277 e 1.299).

Tais poderes e limitações morais e legais objetiva, sem dúvidas, a Justiça social, assunto que examinaremos no seguinte tópico.

Conforme afirma Meirelles ${ }^{16}$ o poder administrativo concedido à autoridade pública tem limites certos e forma lega de utilização. Não é carta branca para arbítrios, violências, perseguições ou favoritismos governamentais. Qualquer ato de autoridade, para ser irrepreensível, deve conformar-se com a lei, com a moral da instituição e com o interesse público. Sem esses requisitos o ato administrativo expõe-se a nulidade. Daí a Administração Pública deve obediência à leis em todas suas manifestações. Até mesmo nas chamadas atividades discricionárias o administrador público fica sujeito às prescrições legais quanto à competência, finalidade e forma, só se movendo com liberdade na estreita faixa da conveniência e oportunidade administrativas.

Todavia, a tal comentário serve-se em acrescentar a necessária observância das normas éticas: moralidade administrativa. Sendo que todo ato administrativo deve ser praticado visando à realização da Justiça social é que aqui consideramos o abuso do poder como ilícito contrário à moral e à lei.

\section{Abuso do poder}

O bom uso do poder implica o emprego do poder conforme a moral e o direito, isto é, observando as normas legais e morais vigorantes, com a finalidade de satisfazer o interesse público. Assim, abusar do poder é empregá-lo fora da moral e da lei, desmerecendo a utilidade pública. ${ }^{17}$

O abuso do poder é, portanto, contrário à Justiça social. Eis que "o poder é confiado ao administrador público para ser usado em benefício da coletividade administrada, no entanto, usado nos justos limites que o bem-

\footnotetext{
${ }^{14}$ MEIRELLES, Hely Lopes. Direito Administrativo Brasileiro. 30. ed. Atualizada por Eurico de Andrade Azevedo, Délcio Balestero Aleixo e José Emmanuel Burle Filho. São Paulo: Malheiros, 2005, p. 133.

${ }^{15}$ Ibidem, p. 133 - 140.

${ }^{16}$ Ibidem, p. 110.
} 
estar social exigir. A utilização desproporcional do poder, o emprego arbitrário da força, a violência contra o administrado, constituem formas abusivas do uso do poder estatal, não toleradas pelo Direito e nulificadoras dos atos que as encerram. O uso do poder é lícito; o abuso, sempre ilícito. Daí por que todo ato abusivo é nulo, por excesso ou desvio de poder". ${ }^{18}$

Confirma Meirelles que o abuso de poder ocorre quando a autoridade, embora competente para praticar o ato, ultrapassa os limites de suas atribuições ou se desvia das finalidades administrativas. $\mathrm{O}$ abuso do poder, como todo ilícito, reveste as formas mais diversas. Ora se apresenta ostensivo como a truculência, às vezes dissimulado como o estelionato, e não raro, encoberto na aparência ilusória dos atos legais. Em qualquer desses aspectos, flagrante ou disfarçado, o abuso do poder é sempre uma (in) legalidade que invalida o ato que o contém. O abuso do poder tanto pode revestir a forma comissiva como a omissiva, porque ambas são capazes de afrontar a lei e causar lesão a direito individual do administrado. ${ }^{19}$

Para Meirelles ${ }^{20}$ o gênero abuso de poder ou abuso de autoridade reparte-se em duas espécies bem caracterizadas: o excesso de poder e o desvio de finalidade. O primeiro ocorre quando a autoridade, embora competente para praticar o ato, vai além do permitido e exorbita no uso de suas faculdades administrativas. Excede, portanto, sua competência legal e, com isso, invalida o ato, porque ninguém pode agir em nome da Administração fora do que a lei lhe permite. O excesso de poder torna o ato arbitrário, ilícito e nulo. É uma forma de abuso de poder que retira a legitimidade da conduta do administrador público, colocando-o na ilegalidade e até mesmo no crime de abuso de autoridade quando incide nas previsões penais da Lei 4.898, de 9.12.65, que visa a melhor preservar as liberdades individuais já asseguradas na CF (art. 50). Já o desvio de finalidade ou de poder verifica-se quando a autoridade, embora atuando nos limites de sua competência, pratica o ato por motivos ou com fins diversos dos objetivados pela lei ou exigidos pelos interesses públicos. O desvio de finalidade ou de poder é, assim, a violação ideológica da lei, ou, por outras palavras, a violação moral da lei, colimando o administrador público os fins não queridos pelo legislador, ou utilizando motivos e meios imorais para a prática de um ato administrativo aparentemente legal. Tais desvios ocorrem, p. ex., quando a autoridade pública decreta uma desapropriação, alegando utilidade pública, mas visando, na realidade, a satisfazer interesse pessoal próprio ou favorecer algum particular com a subsequente transferência do bem expropriado; ou quando outorga uma permissão sem interesses coletivos; quando classifica um concorrente por favoritismo, sem atender aos fins objetivados pela licitação; ou, ainda, quando adquire tipo de veículo com características incompatíveis com a

\footnotetext{
${ }^{17}$ Ibidem, p. 110 - 111.

${ }^{18}$ Ibidem, p. 111.

${ }^{19}$ MEIRELLES, Hely Lopes. Direito Administrativo Brasileiro. 30. ed. Atualizada por Eurico de Andrade Azevedo, Délcio Balestero Aleixo e José Emmanuel Burle Filho. São Paulo: Malheiros, 2005, p. 110 - 111.

${ }^{20}$ Ibidem, p. 112113.
} 
natureza do serviço a que se destinava.

$\mathrm{O}$ ato praticado com desvio de finalidade, continua Meirelles, como todo ato ilícito o imoral ou é consumado às escondidas ou se apresenta disfarçado, sob o capuz da legalidade e do interesse público.

Diante disto, há que ser surpreendido e identificado por indícios e circunstâncias que revelem a distorção do fim legal, substituído habilidosamente por um fim ilegal ou imoral não desejado pelo legislador. A lei regulamentar da ação popular (Lei. 4.717, de 29.6.65) já consigna o desvio de finalidade como vício nulificador do ato administrativo lesivo do patrimônio público e o considera caracterizado quando "o agente pratica o ato visando a fim diverso daquele previsto, explícita ou implicitamente, na regra de competência" (art. 2o, "e", e parágrafo único, "e"). Com essa conceituação legal, o desvio de finalidade entrou definitivamente para nosso Direito Público como causa de nulidade dos atos da Administração.

\section{Corrupção: tipologia, definições e níveis}

O vocábulo corrupção, na área jurídica, é geralmente usado para identificar o fenômeno vinculado ao abuso de poder. Ora, ao falarmos de corrupção na esfera do governo é mister distinguir seus vários tipos, definições e níveis.

Tipologia

Não é o mesmo que falar de corrupção do regime político, da corrupção política o da corrupção administrativa. A "corrupção do regime político" verifica-se nos regimes políticos totalmente corruptos, assim sendo, a corrupção dos funcionários (agentes públicos) normalmente está determinada pelo servilismo ao regime. A corrupção politica é a sabida corrupção dos políticos vinculados ou não a um cargo público. A corrupção administrativa ou dos empregados públicos quer nomeados politicamente quer profissionais, não pode ser desvinculada da corrupção política. Elas se alimentam mutuamente, ainda que o profissionalismo nos serviços públicos possa atenuar a expansão do fenômeno. ${ }^{21}$

A referida tipologia deu origem às diversas definições do fenômeno que, a seguir, examinaremos.

\section{Definições}

Em verdade a corrupção pode ser definida levando em conta variadas perspectivas, a saber, política, econômica, jurídica, sociológica e histórica.

Geralmente ao definir o fenômeno, os doutrinadores se usam de um forte componente valorativo

${ }^{21}$ VILLORIA Mendieta, Manuel. Ética pública y corrupción: Curso de ética administrativa. Madrid: Tecnos, 2000, p. 24. vol.09, no. 04, Rio de Janeiro, 2016.pp. 2526-2544 
indicando a não observação de deveres derivados do exercício de cargos públicos e a um abuso de confiança. Em função desse fato existem definições vinculadas ao abuso de cargo público (abuso de autoridade) ou ao não cumprimento de normas jurídicas por parte dos responsáveis públicos.

Nesse sentido, tem-se definido a corrupção como sendo a utilização de potestades públicas para interesses particulares, qualquer que seja a forma de manifestação, seja em benefício próprio o de terceiros, de partidos políticos, por vínculo de amizade ou por dinheiro etc. (perspectiva política). Como se observa, é um erro pensar que a corrupção unicamente se circunscreve à Administração Pública. A corrupção na Administração Pública é consequência de uma degradação geral dos valores éticos da sociedade. ${ }^{22}$

Todavia, toda conduta do empregado público que, no exercício de cargo, se desvia das obrigações estabelecidas, por razões de interesses privado, familiar etc. pode ser dita de corrupta. Logo, um funcionário corrupto seria aquele que utiliza seu cargo como um negócio (perspectiva econômica), um negócio que tem como fim maximizar benefícios: volume de ingressos e ganâncias.

A corrupção é também atividade ilícita (perspectiva jurídica) geralmente deriva do abuso de poder, quando um agente público, por meios monetários ou de outra natureza não legalmente prevista é induzido a agir favorecendo a que lhe proporciona benefícios. É, também, fenômeno que influi na política pública e agride a satisfação dos interesses sociais (perspectiva sociológica). Com tal definição se inicia um debate sobre a atuação das pessoas e grupos que comercializa seus contatos e influências (tráfico de influências) e suas conexões com os empregados públicos de nível superior, garantindo decisões favoráveis, geralmente, sobre políticas públicas a favor de interesses particulares, exemplo: financiamento de partidos, doações e contribuições para campanhas etc.

Uma perspectiva histórica indica que o fenômeno estudado também evolui, isto porque condutas hodiernamente consideradas corruptas foram perfeitamente válidas noutros contextos históricos.

Atualmente, todos se dizem reféns de um Estado corrupto, que serve dobra unicamente aos interesses da camada social mais favorecida. A corrupção é mesmo um fenômeno, resultado da decomposição (corrosão) moral política e administrativa. É uma perturbação ao progresso econômico-social, que engendra e perpetua a pobreza e que agride a ordem econômica nacional. É a negação da vida e da dignidade humana, que junto à apatia, ao conformismo e ao deficiente planejamento econômico causa o que pode ser dito de calamidade (caos) social expressa em inúmeras carências: saúde, insegurança, violência, analfabetismo etc. e para a qual se deve reservar severas sanções sociais: jurídico-morais.

A corrupção é forma de degradação dos valores éticos na Administração Pública. A corrupção já não é um fato isolado, mas é um fenômeno que agride a Ética e os direitos de cada ser humano, a dignidade, a liberdade, a paz e a Justiça social. Eis que o respeito dos direitos sociais é um dever que assegura nosso próprio direito é

\footnotetext{
${ }^{22}$ DURÁN Martínez, Augusto. Derechos Humanos y Corrupción Administrativa. A \& C. Revista de Direito Administrativo e vol.09, nº. 04, Rio de Janeiro, 2016. pp. 2526-2544 2535
} 
pressuposto necessário do Estado Democrático.

Logo, existe uma conexão evidente entre a Ética e os Direitos Humanos (direitos de primeira, segunda e terceira geração) e aqueles que derivam da condição de pessoa humana (personalidade) que, devido a nossas próprias imperfeições os ignoramos, mas que com o futuro desenvolvimento cultural podemos descobrir e superar. Eis que o homem, além do "direito à vida" também possui o "direito a viver" direito de viver que não é justamente aquele que concerne só ao começo e ao fim da vida. É o direito que existe durante toda a vida humana e que anda na dimensão biológica, cultural, econômica, social, ética fundada num conteúdo integral próprio de cada indivíduo. ${ }^{23}$

A corrupção é uma espécie de atentado à Ética que afeta o direito a viver e que supõe um desconhecimento da dignidade humana. A Convenção Interamericana Contra a Corrupção (no Preâmbulo) parte da seguinte concepção:

CONVENCIDOS de que la corrupción socava la legitimidad de las instituciones públicas, atenta contra la sociedad, el orden moral y la justicia, así como contra el desarrollo integral de los pueblos;

CONSIDERANDO que la democracia representativa, condición indispensable para la estabilidad, la paz y el desarrollo de la región, por su naturaleza, exige combatir toda forma de corrupción en le ejercicio de las funciones públicas, así como los actos de corrupción específicamente vinculados con tal ejercicio: $[\ldots]$

O combate contra a corrupção não se vislumbra como um fim em si mesmo, mas como meio de proteção e desenvolvimento do "direito de viver", pela defesa da democracia e da economia (meios para o desenvolvimento da pessoa humana). Logo, o verdadeiro fim da luta contra a corrupção é o desenvolvimento dos direitos humanos em toda sua magnitude. Eis que sem democracia e sem um nível econômico razoavelmente adequado, não há desenvolvimento da pessoa humana, nem possibilidade de se falar seriamente de direitos humanos. Por isso Gordillo vinculou tal Convenção com os tratados de direitos humanos. ${ }^{24}$

\section{Níveis}

A anterior teorização do fenômeno da corrupção nos leva a aceitar que existem dois níveis de corrupção:

Primeiro, a corrupção absoluta (ou totalmente inaceitável) que inclui todo um conjunto de atos condenados tanto pelas elites morais do país como pela cidadania em geral, onde parece existir uma dada congruência entre a lei e a opinião pública. Exemplo: o desvio de dinheiro público.

Segundo, a corrupção relativa ou ambígua em que não há um consenso, ou seja, alguns setores ficam a

Constitucional. Ano 4, n. 15, jan/mar. 2004. Belo Horizonte: Fórum, 2004, p. 43.

${ }^{23}$ DURÁN Martínez, Augusto. Derechos Humanos y Corrupción Administrativa. A \& C. Revista de Direito Administrativo e Constitucional. Ano 4, n. 15, jan/mar. 2004. Belo Horizonte: Fórum, 2004, p. 39 - 41.

${ }^{24}$ GORDILlo, A. Tratado de Derecho Administrativo. Fundación de Derecho Administrativo. Buenos Aires, 1997, t.1, Parte General, 4. edición, p. XVI-7, apud, DURÁN Martínez, Augusto. Derechos Humanos y Corrupción Administrativa. A \& C. Revista de Direito Administrativo e Constitucional. Ano 4, n. 15, jan/mar. 2004. Belo Horizonte: Fórum, 2004, p. 42. 
favor e outros contra uma possível condenação. Pode acontecer que existam normas ou sanções sociais, no entanto uma parte da população não considera a conduta como sendo anormal. Exemplo, tráfico de influências.

Ora, pode acontecer que, de acordo ao contexto (tempo e lugar) a corrupção relativa passe a ser considerada absoluta.

Em suma, a corrupção pode se manifestar em toda a projeção da atividade de política-administrativa.

\section{Duas soluções possíveis para o combate da corrupção}

O fenômeno "corrupção", em geral e administrativa, em particular, pode e deve ser combatido de formas, a saber: A) Direta ou imediata (extremo controle) e; B) Indireta ou mediata (por meio de uma educação que objetive as bases para uma consciência moral: razoável e universal).

\section{Direta ou imediata}

Num primeiro olhar percebe-se o contato entre o poder administrativo e o homem como chave para um funcionamento adequado do Estado de Direito e para o pleno desenvolvimento dos direitos humanos. Certamente a "administração da justiça" não é considerada missão da Administração, mas o "dever de administrar com justiça" é premissa para uma boa administração. Então, existindo corrupção administrativa não se estará administrando com justiça, assim sendo, não há Estado de Direito e, portanto, não há direitos humanos. Conforme explica Augusto Durán Martinez o problema recai na má aplicação do Direito. É, conforme o autor, o talão de Aquiles dos direitos humanos no Uruguai, onde existe uma denominada "administração paralela" que vigora fora dos limites dos Direitos, por meio de normas e princípios próprios, incompatíveis com o sistema jurídico formal. ${ }^{25}$

Constata-se, continua o citado autor, que na realidade latino-americana existem países que possuem códigos de procedimento administrativo (p.x. Uruguai) e outros não. Mas, se verifica que não há muitas diferenças entre os países que já regularam tal procedimento e os que não têm legislado sobre o assunto. O pior é que a Lei de Procedimento Administrativo (ainda tecnicamente equipada e feita seguindo o melhor critério jurídico), nao se cumpre eficazmente. Transformando-se de instrumento social em mero instrumento literário.

Ora, perante a falta de ineficácia e de aplicabilidade das normas e princípios impõem-se soluções a exigência da aplicação das normas e sanções vigorantes. Talvez a solução não esteja em criar novas normas ou em elevar o tecnicismo das normas, mas em procurar modelos e mecanismos que garantam a observância das normas morais e jurídicas vigentes.

\footnotetext{
${ }^{25}$ DURÁN Martínez, Augusto. Derechos Humanos y Corrupción Administrativa. A \& C. Revista de Direito Administrativo e Constitucional. Ano 4, n. 15, jan/mar. 2004. Belo Horizonte: Fórum, 2004, p. 43 - 46. 
Ademais, afirma Augusto Durán ${ }^{26}$, poderia ser pensada a possibilidade de criação de um Ombudsman, isto é, uma instituição para a proteção dos direitos civis e políticos de individuais e dos direitos econômicos, sociais e culturais da coletividade. Como se observa a solução não traz unicamente a repressão ou a adoção de novas formas de controle.

\section{Indireta ou mediata}

O fato de ser reconhecida a existência de uma degradação geral de valores éticos: alarmante tendência a violar os grandes princípios e normas constitucionais e a subversão de fins colocando-se os interesses específicos como presidindo o bem comum, premissa das concepções filosóficas erradas, faz concluir que estamos ante um problema "cultural" e um problema cultural só se combate eficazmente por meio de um adequado sistema educativo. Conforme indica Augusto Duran, um adequado sistema educativo é aquele que logra transmitir os valores adequados. ${ }^{27}$

Basta reconhecer a necessidade de implantação de políticas públicas contra a corrupção, contudo, é mister um estudo das condições socioculturais de cada país e de cada região, levando em conta que as normas jurídicas não podem ser consideradas o único meio de combate à corrupção ou fator determinante das novas mudanças. Assim, propõe-se a ideia de uma educação que objetive a formação de uma consciência social: jurídica e moral, base para uma consciência moral razoável e universal.

\section{O controle como instrumento de combate à corrupção e à pobreza}

O extremo controle condicional àqueles que ocupam e ocuparão cargos públicos é um meio que implica: uma séria, rigorosa e constante fiscalização, além de ter que ser de domínio de toda a população destinatária e eleitora. Portanto, é necessária uma Lei especial para uma situação especial, tese essa que hoje alcança uma notada preponderância perante a irresponsabilidade do administrador público.

Importante, em extremo, é a instrumentação de mecanismos que propiciem uma eficaz fiscalização dos recursos e do resultado do desempenho dos agentes públicos. Alguns outros aspectos, tais como: a forma de preenchimento de cargos, promoções etc. devem atender a critérios morais.

\section{A Educação como instrumento de combate à corrupção e à pobreza}

A educação como meio indireto ou mediato há de possibilitar a reinversão dos conceitos política e negócio.

\footnotetext{
${ }^{26}$ Ibidem, 2004, p. 53.
} 
Educar para uma consciência jurídico-moral é formar nas crianças e nos jovens um caráter respeitoso e criador. É ensinar, a saber, exigir e cumprir, isto é, a ser exigente e a ser respeitoso, cumpridor, observar e agir dentro das normas morais.

É, de fato, evidente a inter-relação existente entre a imoralidade, a burocracia, a ilegalidade, a miséria, o bom senso e a falta de educação.

Destarte, sem educação não há garantia de qualquer convivência dentro do marco da moral e do direito. Assim, sendo a efetividade da moralidade pressuposto da administração pública, devemos inferir que a educação é a base para uma administração eficiente. A educação é condição essencial para uma maior eficiência administrativa.

Eis que a educação inibe o ato quer imoral quer ilícito; logo, a educação torna desnecessário o castigo por força da moral e da lei. O investimento na educação, portanto, investimento na edificação de uma sociedade sadia, culta e responsável é, de fato, uma das maiores obras do Estado democrático em construção.

Quando falamos em educação de um país devemos saber separar o que é de responsabilidade pública do que é de responsabilidade particular. Todavia, o que é de responsabilidade familiar e o que passou a ser responsabilidade da Escola e das demais instituições quer governamentais quer não governamentais e, assim, $\mathrm{o}$ que é objeto econômico (lucro) do que é de interesse sociocultural.

O direito à educação constitui um dever correlato de um sujeito determinado: o Estado - que, por isso, tem a obrigação de satisfazer aquele direito. Se este não é satisfeito, não se trata de programaticidade, mas de desrespeito ao direito, de descumprimento da norma. ${ }^{28}$

"O direito à educação é direito fundamental social que obteve reconhecimento expresso no art. $6^{\circ}$ de nossa Constituição, integrando, portanto, o catálogo dos direitos fundamentais e sujeito ao regime jurídico reforçado a estes atribuído pelo Constituinte (especialmente art. $5^{\circ}, \S 1^{\circ}$, e art. $6^{\circ}, \$ 4^{\circ}$, inc. IV)”.

No título da ordem social, a educação foi objeto de regulamentação mais detalhada no capítulo III (art. 205 até 214), razão pela qual também aqui se coloca a questão preliminar de quais os dispositivos que efetivamente podem ser considerados como fundamentais, à luz do dispositivo no art. $5^{\circ}, \$ 2^{\circ}$, de nossa Carta" ${ }^{29}$ (cuja eficácia é duvidosa).

"Com efeito, o art. 205, ao dispor que: A educação, direito de todos e dever do Estado e da família, será promovida e incentivada com a colaboração da sociedade, está, na verdade, revelando uma feição notadamente programática e impositiva, mas, de eficácia limitada. Apenas estabelece fins genéricos a serem alcançados, e diretrizes a serem respeitadas pelo Estado e pela comunidade na realização do direito à educação, quais sejam, o

\footnotetext{
${ }^{27}$ Idem.

${ }^{28}$ SILVA, José Afonso da. Aplicabilidade das normas constitucionais. 6. ed. São Pulo: Malheiros, 2004, p. 150. vol.09, nº. 04, Rio de Janeiro, 2016.pp. 2526-2544
} 
pleno desenvolvimento da pessoa, seu preparo para o exercício da cidadania e sua qualificação para o trabalho. Em contrapartida, vislumbra-se que o art. 207 se caracteriza como típica garantia institucional fundamental, assegurando a autonomia universitária”. ${ }^{30}$

De qualquer forma, "o Estado é peça relevante do jogo entre o sistema jurídico e o sistema político" ${ }^{31}$. "Cuida-se, também neste particular, do clássico dilema do Estado social no que concerne às funções precípuas, isto é, se deve limitar-se à tarefa de assegurar um patamar mínimo em prestações materiais, destinadas a promover a igualdade material no sentido de uma igualdade de oportunidades (ajuda para a autoajuda) ou se deve (a despeito da efetiva possibilidade alcançar tal objetivo) almejar um padrão ótimo nesta seara”. ${ }^{32}$

O Estado pode ser definido como "a ordem jurídica soberana que tem por fim o bem comum de um povo situado em determinado território (...). A politicidade do Estado é afirmada na referência expressa ao bem comum". 33

A busca do "bem comum", em sociedades complexas, fragmentadas, excludentes e nada igualitária, como no caso brasileiro, também é perturbador. Numa sociedade que nega os direitos fundamentais da pessoa humana a parcelas significativas da população, a regra da maioria assume a feição de instrumento de autolegitimação da autoridade. Sem respeito aos direitos humanos, a participação política livre e igualitária torna-se utópica. A simples procura do "bem-comum" é o suficiente para caracterizar as finalidades do Estado $?^{34}$

A ética no planejamento e controle do custo de produção poderia vir a ser um fator importante para a diminuição do preço dos produtos, para o crescimento econômico, para o aumento do consumo e, consequentemente, para a diminuição do desemprego etc. e, finalmente, para a realização dos valores humanos expressos por meio de princípios constitucionais (ex. o princípio da isonomia).

Com relação à educação e treinamento profissional, amplo consenso afirma ser essa a chave do verdadeiro desenvolvimento econômico e social. Na produção, o único elemento essencial e insubstituível é o trabalho, e trabalho são pessoas, isto é, o fator humano. Este que pode ser entendido em dois sentidos: como as características culturais de um país e como resultado da educação, ou seja, do nível de instrução e capacitação profissional da população. ${ }^{35}$

Países que privilegiaram a escravidão e a acumulação de riquezas trazidas de outras regiões do mundo

\footnotetext{
${ }^{29}$ SARLET, Ingo Wolfgang. A eficácia dos direitos fundamentais. 3. ed. ver. atual. e ampl. Porto Alegre: Livraria do Advogado, 2003, p. 317.

${ }^{30} \mathrm{Ibid}, \mathrm{p} .318-319$.

${ }^{31}$ CAMPILONGO, Celso Fernandes. Direito e Democracia. São Paulo: Max Limonad. 1997, p. 107.

${ }^{32}$ SARLET, Ingo Wolfgang. A eficácia dos direitos fundamentais. 3. ed. ver. atual. e ampl. Porto Alegre: Livraria do Advogado, 2003, p. 314-315.

${ }^{33}$ DALLARI, Dalmo de Abreu. Elementos de teoria geral do estado p. 100-101, apud, CAMPILONGO, Celso Fernandes. Direito e Democracia. São Paulo: Max Limonad. 1997, p. 109.

${ }^{34}$ CAMPILONGO, Celso Fernandes. Direito e Democracia. São Paulo: Max Limonad. 1997, p. 110. vol.09, no. 04, Rio de Janeiro, 2016.pp. 2526-2544 
viram-se condenados ao estancamento econômico, em relação aos países que privilegiaram a industrialização e o desenvolvimento cultural e intelectual.

Alterar o perfil da distribuição de renda é uma meta a ser perseguida em longo prazo, mediante uma política adequada em todos os níveis. A educação, sob essa perspectiva, deve ser considerada um condicionante ético do desenvolvimento econômico e humano. Para alcançar uma melhor distribuição de renda, é preciso oferecer os meios para que os pobres possam ganhar a vida dignamente. Sob esse ponto de vista, a educação adquire particular relevância como alavanca do verdadeiro desenvolvimento pessoal e humano. Por meio da erradicação do analfabetismo e da educação formal, o pobre tem acesso a um mercado de trabalho que permitirá a ele sair da pobreza sem esperar que um elevado crescimento econômico geral solucione sua situação em um futuro distante e ignorado.

Pode-se afirmar que o crescimento econômico é algo desejável, em termos éticos, à medida que pode contribuir para o aperfeiçoamento das pessoas e da sociedade. A questão-chave desse processo encontra-se no âmbito educacional, em proporcionar os recursos educativos que permitam às pessoas ganhar a vida honestamente. ${ }^{36}$

Eis o caminho para que o ser humano tenha acesso ao mundo de informação com dignidade.

\section{CONCLUSÃO}

A sociedade deve possibilitar que todo cidadão tenha ou adquira as mesmas condições e possibilidades de poder satisfazer suas necessidades espirituais e materiais. Daí vale realçar a importância do princípio "a cada um os mesmos" ou "a cada um as mesmas possibilidades que a própria sociedade é capaz de conceder a todos". Sendo assim, a inclusão social é pensada como uma forma de garantir a Justiça social e a cidadania.

Logo, trata-se de proporcionalidade e não de igualdade. O conceito de igualdade aparece como um ideal abstrato ou inalcançável, já a proporcionalidade pode ser medida, calculada e exigida.

A proporcionalidade não será o resultado da medição das necessidades familiares ou individuais. Vale garantir a oportunidade e não suprir as necessidades familiares por conta de programas e bondades dos governos. Significa isso, dar a cada um as garantias e direitos que são próprios da Convivência Social: educação, saúde, segurança, inclusão social etc.

O ideal de igualdade é vago e subjetivo, a procura pela realização de certa igualdade engendra insatisfação, conflitos e mais injustiça. Por exemplo, as regalias ou concessões (paternalismos) governamentais operam como pura fantasia dentro de um ideal utópico e inalcançável de bem-estar social.

${ }^{35}$ ARRUDA, Maria Cecília Coutinho de, e outros. Fundamentos de ética empresarial e econômica. 2. ed. São Paulo: Atlas, 2003, p. 169-170.

${ }^{36}$ Ibidem, 2003, p. 171. 
A Justiça social se refere à participação possível do cidadão nos processos de produção, distribuição, intercâmbio e consumo. Veja-se que toda injustiça social (problemas e conflitos humanos) está conectada a alguns desses quatro indicadores, geralmente prescritos, com o rótulo de "ordem econômica", na legislação de cada país.

Vemos, por isso, incertas e superadas toda tentativa de realização da Justiça social através do direito, isto é, por meio de uma leitura estruturalista - positivista que unicamente nos fala da legalidade e não da Justiça.

A injustiça social é um problema que nasce da distribuição da própria justiça. É Justiça social negada pela ordem econômica, pela política e pelo direito.

Logo, vale realçar o caráter funcionalista do direito e da Administração Pública em face da Justiça e da Convivência Social. Daí que a ineficiência e o abuso de poder (como postura egoísta e individualista) negam a Justiça social: a Justiça social é construto que justifica o bom uso dos poderes, instrumento que objetiva a satisfação dos interesses coletivos.

Conclui-se que a corrupção é um fenômeno que limita e inviabiliza a concretização da justiça social. Este fenômeno pode ser combatido de duas maneiras, a saber, direta ou imediata por meio de um extremo controle e, indireta ou mediata, isto é, por meio de uma educação que objetive as bases para uma consciência moral: razoável e universal. Cabe aos Estado, aos Governos e a seus agentes públicos tomar consciência acerca da importância da educação como instrumento de combate à pobreza.

\title{
JUSTICE, CORRUPTION AND POWER: EDUCATION AS AN INSTRUMENT TO FIGHT POVERTY
}

\begin{abstract}
The central proposal of the present study is to discuss the possible correlation between Public Power, Corruption and Social Justice. It is a matter of concern with the historical and contemporary conception of the constructs Public Ethics, Corruption, Justice and Social Justice. Based on a conceptual and axiological approach, Justice is discussed as an abstract concept, vague and relative, but that can be defined according to the purpose of moral Philosophy and Law in the face of human coexistence. It is concluded that Social Justice is the fundamental premise for the realization of rights and Citizenship.
\end{abstract}

Keywords: Justice. Education. Corruption. Poverty.

\section{REFERENCIAS}

ALEXY, Robert. Teoría de los Derechos Fundamentales, trad. de Ernesto Garzón Valdés, Madrid: Centro de Estudios Constitucionales, 1993. 
ARRUDA, Maria Cecília Coutinho de, e outros. Fundamentos de ética empresarial e econômica. 2. ed. São Paulo: Atlas, 2003.

ASHLEY, Patrícia Almeida (Coord.) Ética e Responsabilidade Social nos Negócios. 2. ed. São Paulo: Saraiva, 2005. (p. 10-76)

CAMPILONGO, Celso Fernandes. Direito e Democracia. São Paulo: Max Limonad. 1997.

DURÁN Martínez, Augusto. Derechos Humanos y Corrupción Administrativa. A \& C. Revista de Direito Administrativo e Constitucional. Ano 4, n. 15, jan/mar. 2004. Belo Horizonte: Fórum, 2004.

DWORKIN, Ronald. Taking Rights Seriously, Massachussets: Harvard University Press, 1980.

ENTERRÍA, Eduardo García de \& Tomás-Ramon Fernández. Curso de Derecho Administrativo, vol. I, 2. ed., Madrid: Editora Civitas, 1978.

FERNÁNDEZ Secado Francisco. La Dignidad de la Persona como Valor Supremo del Ordenamiento Jurídico Español y como Fuente de todos los Derechos. A \& C. Revista de Direito Administrativo e Constitucional. Ano 4, n. 18, out/dez. 2004. Belo Horizonte: Fórum, 2004, p. 11 - 42.

FREITAS, Juarez. O Controle dos Atos Administrativos e os Princípios Fundamentais, São Paulo: Malheiros, 1997, p. 67-68.

MARTINS JÚNIOR, Wallace Paiva. Probidade Administrativa. São Paulo: Saraiva, 2001.

MEIRELLES, Hely Lopes. Direito Administrativo Brasileiro. 30. ed. Atualizada por Eurico de Andrade Azevedo, Délcio Balestero Aleixo e José Emmanuel Burle Filho. São Paulo: Malheiros, 2005.

OSÓRIO, Fábio Medina. Improbidade Administrativa. 2. ed. Porto Alegre: Síntese, 1998.

PERELMAN, Chaïm. Ética e direito. Trad. Maria Ermantina de Almeida Prado Galvão. 2. ed. São Paulo: Martins Fontes, 2005.

ROSS, Alf. Direito e Justiça. Trad. Edson Bini. Revisão técnica Alysson Leandro Mascaro. Bauru, São Paulo: EDIPRO, 2000.

SANDEL, Michael J. Justiça - O que é fazer a coisa certa. Trad. de Heloisa Matias e Maria Alice Máximo. 10. ed. Rio de Janeiro: Civilização Brasileira, 2013.

SARLET, Ingo Wolfgang. A eficácia dos direitos fundamentais. 3. ed. ver. atual. e ampl. Porto Alegre: Livraria do Advogado, 2003.

SILVA, José Afonso da. Aplicabilidade das normas constitucionais. 6. ed. São Pulo: Malheiros, 2004.

SKORUPSKI, John. Ética, in BUNNIN, Nicholas e E.P. Tsui-James (orgs). "Compêndio de Filosofia”. São Paulo: Loyola, 2002.

VILLORIA Mendieta, Manuel. Ética pública y corrupción: Curso de ética administrativa. Madrid: Tecnos, 2000. 
Quaestio Iuris

Trabalho enviado em 27 setembro de 2016.

Aceito em 01 de novembro de 2016. vol. 09, n. 04, Rio de Janeiro, 2016. pp. 2526-2544 DOI: $10.12957 /$ rqi.2016.25806 